\title{
Radical Copolymerization of 2-Vinylnaphthalene with Maleic Anhydride. Characterization of the Microstructure of the Resulting Copolymer by Fluorescence Spectroscopy
}

\author{
Weiping ZENG and Yasuhiko SHIROTA* \\ Department of Applied Chemistry, Faculty of Engineering, \\ Osaka University, Yamadaoka, Suita, \\ Osaka 565, Japan
}

(Received January 9, 1989)

\begin{abstract}
Microstructure of the copolymer of 2-vinylnaphthalene (2-VN) with maleic anhydride obtained by radical initiation over a wide range of monomer feeds has been characterized by fluorescence spectroscopy and composition data. The microstructure of the copolymer varies depending on the monomer composition in spite of the fact that copolymer compositions are close to $1: 1$. The $2-\mathrm{VN}-2-\mathrm{VN}$ diad fraction is shown to increase with the $2-\mathrm{VN}$ molar fraction in the monomer feed. Polymerization temperature is found to affect significantly the microstructure of the copolymer.
\end{abstract}

KEY WORDS Poly(2-vinylnaphthalene-co-maleic anhydride) / Radical copolymerization / Microstructure / Fluorescence Spectroscopy / Temperature Effect /

Free-radical copolymerizations of electrondonor monomers with electron-acceptor monomers tend to form copolymers with approximately $1: 1$ compositions over a wide range of monomer compositions, and certain systems yield $1: 1$ alternating copolymers regardless of the monomer feed composition. Such radical copolymerizations have been a subject of numerous studies from both synthetic and mechanistic interests. ${ }^{1-4}$ Typical electronacceptor monomers that undergo $1: 1$ alternating radical copolymerization are maleic anhydride (MAn), sulfur dioxide, and di- and trisubstituted ethylenes with cyano or carboalkoxy groups. Corresponding electron-donor monomers include aryl vinyl monomers such as styrene and $N$-vinylcarbazole, vinyl ethers and vinyl sulfides.

In contrast to extensive studies on the styrene-MAn system, known to be a $1: 1$ alternating copolymerization system ${ }^{5.6}$ there have been only a few studies on the vinyl- naphthalene-electron-acceptor monomer systems. It has been reported that the copolymerization of 2-vinylnaphthalene $(2-\mathrm{VN})$ with methyl methacrylate yields random copolymers, but that the copolymerization in the presence of ethylaluminum sesquichloride produces a $1: 1$ alternating copolymer. ${ }^{7-9}$ Recently a 2-VN-MAn copolymer was prepared by the radical copolymerization of $2-\mathrm{VN}$ with MAn as a precursor to amphiphilic copolymers and shown to be a $1: 1$ alternating copolymer based on the composition data. ${ }^{10}$

Characterization of copolymers as $1: 1$ alternating copolymers is usually based on the fact that copolymers with equimolar composition are obtained over a wide range of monomer feed ratios. The equimolar composition of copolymers, however, does not necessarily mean that they are truely $1: 1$ alternating copolymers. In addition, there is a limitation in the accuracy of the copolymer composition, which has usually been determined by elemen- 
tal analysis, infrared absorption spectroscopy, or chemical analysis. It is necessary to distinguish real $1: 1$ alternating copolymers from copolymers with a statistical $1: 1$ composition; however, there have been few studies on the microstructure of hitherto reported $1: 1$ alternating copolymers and copolymers with compositions close to $1: 1$.

In our studies of alternating radical copolymerizations $^{11-18}$ we reported that radical copolymerizations of $N$-vinylcarbazole with fumaronitrile $^{11.13}$ and diethyl fumarate ${ }^{12,13}$ produce $1: 1$ alternating copolymers over a wide range of monomer feed compositions and that these $1: 1$ alternating copolymers exhibit only monomer fluorescence due to the carbazole chromophore ${ }^{13,19}$ : this provides an evidence for the 1:1 alternating structure. 1:1 Alternating copolymers prepared by radical copolymerizations in the presence of ethylaluminum sesquichloride, e.g., poly(2-VN-altmethyl methacrylate) and poly(styrene-altmethyl methacrylate), have also been reported to show only monomer fluorescences. ${ }^{7}$ It is expected that examination of the fluorescence spectra of copolymers as a function of the monomer feed composition should provide information on the microstructure of copolymers, in particular, for the distinction of the real $1: 1$ alternating copolymer from copolymers with a statistical 1:1 composition.

We report here the characterization of the microstructure of the copolymer of 2-VN with MAn, produced by the AIBN-initiated radical copolymerization of 2-VN with MAn over a wide range of monomer feeds, by fluorescence spectroscopy and composition data. ${ }^{20}$ The effect of polymerization temperature on the microstructure of the resulting copolymer is also examined.

\section{EXPERIMENTAL}

\section{Materials}

2-Vinylnaphthalene (Aldrich Chem. Co., Inc.) was chromatographed over silica gel (eluent: $n$-hexane), then recrystallized from ethanol, and dried in vacuo. Maleic anhydride (Wako Chemical Industries, Ltd., extra pure grade) was chromatographed over silica gel, recrystallized from benzene and then sublimed twice in vacuo immediately before use. Benzene was purified by washing with (i) concentrated sulfuric acid, (ii) dilute aqueous sodium hydroxide, (iii) deionized water; it was then dried over calcium chloride and over metallic sodium before distillation. Tetrahydrofuran (THF) was refluxed over potassium hydroxide and distilled; it was further purified by distillation over lithium aluminum hydride.

\section{Copolymerization}

The radical copolymerization of $2-\mathrm{VN}$ with MAn was carried out in toluene at $0{ }^{\circ} \mathrm{C}$ and in benzene at $30,60,80$, and $90^{\circ} \mathrm{C}$. The total monomer concentration was $0.5 \mathrm{~mol} \mathrm{dm}^{-3}$ in toluene and $1.0 \mathrm{~mol} \mathrm{dm}^{-3}$ in benzene. The initiators used for the polymerizations in toluene at $0^{\circ} \mathrm{C}$, in benzene at $30^{\circ} \mathrm{C}$, and in benzene at higher temperatures were $2,2^{\prime}$ azobis(4-methoxy-2,4-dimethylvaleronitrile) (AMDVN), 2,2'-azobis(2,4-dimethylvaleronitrile) (ADVN), and AIBN, respectively. The concentrations of AMDVN, ADVN, and AIBN were $1.0 \times 10^{-2}, 1.0 \times 10^{-2}$, and $1.25 \times$ $10^{-2} \mathrm{~mol} \mathrm{dm}^{-3}$, respectively. The polymerization was stopped at less than $8 \%$ conversion based on total quantities of the monomers. The copolymers obtained were dissolved in acetone and reprecipitated repeatedly from $n$ hexane-benzene $(9: 1, \mathrm{v} / \mathrm{v}$ ratio), and dried in vacuo.

\section{Measurements}

Copolymer compositions were determined from carbon content in elemental analysis. The fluorescence spectra of the 2-VN homopolymer and copolymers were measured in THF mostly at a concentration of $c a .2 \times 10^{-4} \mathrm{~mol} \mathrm{dm}^{-3}$ based on the $2-\mathrm{VN}$ unit. The excitation wavelength was $280 \mathrm{~nm}$ for both the $2-\mathrm{VN}$ homopolymer and the copolymers. The electronic 
absorption spectra and fluorescence spectra were taken with a Hitachi U-3200 spectrophotometer and a Hitachi 850 fluorescence spectrometer, respectively. Molecular weights of the copolymers were determined by gelpermeation chromatography with a Shimadzu LC5A system using polystyrene as a standard.

\section{RESULTS AND DISCUSSION}

The copolymerization of 2-VN with MAn in the presence of a free-radical initiator produced a copolymer, poly(2-VN-co-MAn). Table I summarizes compositions and molecular weights of poly(2-VN-co-MAn) obtained by AIBN-initiated copolymerization at $60^{\circ} \mathrm{C}$ in benzene. The results show that the compositions of the copolymers obtained at monomer feed compositions in large excess of either 2-VN or MAn deviate from the $1: 1$ composition but that the copolymers obtained at the $2-\mathrm{VN}$ feed ratio from 0.40 to 0.60 have nearly $1: 1$ compositions.
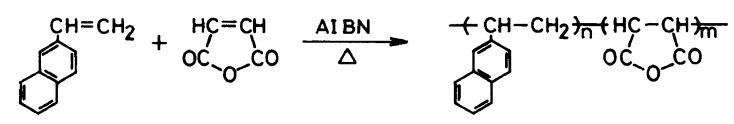

Figure 1 shows the fluorescence spectra of poly(2-vinylnaphthalene) (poly(2-VN)) and poly(2-VN-co-MAn) with near equimolar compositions. Poly(2-VN) exhibits both excimer and monomer fluorescences with peaks at $400 \mathrm{~nm}$ and $338 \mathrm{~nm}$, respectively. ${ }^{21}$ The present results show that the poly(2-VN-co-MAn) also exhibits both monomer and excimer fluorescences in spite of the fact that the copolymer composition is approximately $1: 1$;

Table I. Compositions and molecular weights of poly(2-VN-co-MAn) obtained at $60^{\circ} \mathrm{C}^{\mathrm{a}}$

\begin{tabular}{|c|c|c|c|}
\hline $\begin{array}{l}\text { 2-VN mole } \\
\text { fraction in } \\
\text { monomer feed }\end{array}$ & $\begin{array}{l}\text { 2-VN mole } \\
\text { fraction in } \\
\text { copolymer }\end{array}$ & $M_{n} \times 10^{-4}$ & $M_{w} \times 10^{-4}$ \\
\hline 0.10 & 0.44 & 0.7 & 1.3 \\
\hline 0.20 & 0.46 & 0.7 & 2.2 \\
\hline 0.30 & 0.46 & 1.6 & 3.8 \\
\hline 0.40 & 0.49 & 1.4 & 7.8 \\
\hline 0.50 & 0.50 & 4.4 & 7.6 \\
\hline 0.60 & 0.51 & 4.0 & 9.9 \\
\hline 0.70 & 0.53 & 5.8 & 17 \\
\hline 0.80 & 0.57 & 8.5 & 51 \\
\hline 0.92 & 0.66 & 4.5 & 20 \\
\hline
\end{tabular}

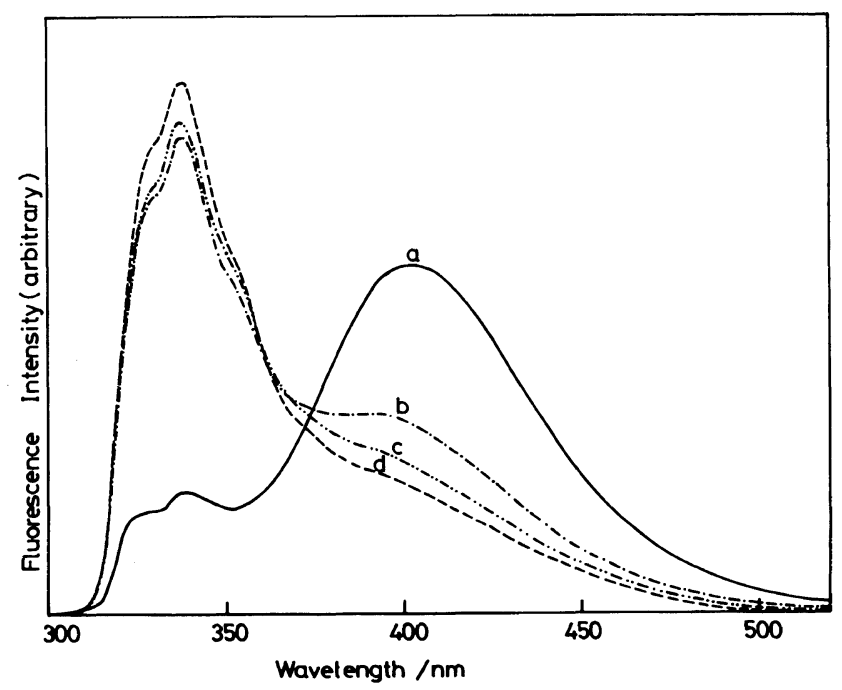

Figure 1. Fluorescence spectra of poly(2-vinylnaphthalene) and poly(2-VN-co-MAn) obtained at $60 \mathrm{C}$ in benzene. The spectra were measured in THF at room temperature. a) poly(2-vinylnaphthalene); b) - d) poly(2-VN-co-MAn). 2-VN molar fraction in the monomer feed: b) $0.6 ;$ c) 0.5 ; d) 0.4 . 
the relative intensity of the excimer fluorescence to the monomer fluorescence increases with the molar fraction of $2-\mathrm{VN}$ in the monomer feed. No change in the ratio of the excimer to the monomer fluorescence intensity was observed when the copolymer concentration based on the 2-VN unit was varied from $4 \times 10^{-5}$ to $1 \times 10^{-3} \mathrm{~mol} \mathrm{dm}^{-3}$. It is therefore concluded that the excimer fluorescence observed at ca. $2 \times 10^{-4} \mathrm{~mol} \mathrm{dm} \mathrm{d}^{-3}$ concentration is intramolecular in nature.

Figure 2 shows the ratios of the excimer to the monomer fluorescence intensity, $I_{400} / I_{338}$, for poly(2-VN-co-MAn) obtained at $60^{\circ} \mathrm{C}$ in benzene vs. monomer feed compositions. The copolymer compositions are also figured. It is clearly shown that the value of the fluorescence intensity ratio depends significantly on the monomer feed composition, increasing with the 2-VN molar fraction in the monomer composition.

Generally, the intramolecular excimer formation in aryl vinyl polymers in a dilute solution using good solvents occurs by the nearest-neighbor interactions as reported for polystyrene, poly(2-VN) and poly $(N$-vinylcarbazole), ${ }^{7,19,21}$ although the excimer formation by non-nearest-neighbor interactions has also been observed for poly(acenaphthylene)

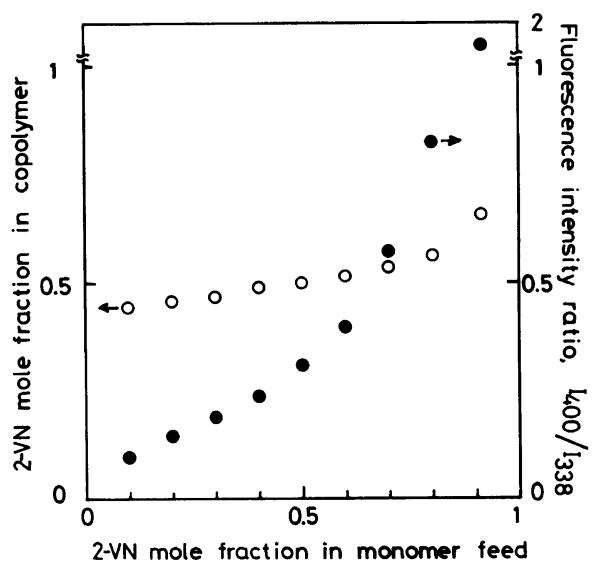

Figure 2. Compositions $(\bigcirc)$ and fluorescence intensity ratios $(\bigcirc), I_{400} / I_{338}$, of poly (2-VN-co-MAn) obtained at $60^{\circ} \mathrm{C}$ in benzene vs. monomer feed compositions. in which nearest-neighbor interactions are structurally impossible. ${ }^{22}$ The appearance of the intramolecular excimer fluorescence in poly(2-VN-co-MAn) indicates the existence of the 2-VN-2-VN diad sequence even in the copolymer with a composition close to $1: 1$. Significant differences in the relative intensity of the excimer to the monomer fluorescence for poly(2-VN-co-MAn) obtained at various monomer feed ratios indicate that the microstructure of poly(2-VN-co-MAn) varies significantly depending on the monomer feed composition at which the copolymer is produced.

It is known that the intramolecular excimer formation in vinyl aromatic polymers generally takes place via energy migration between pendant aromatic chromophores along the polymer chain. The ratio of the excimer to the monomer fluorescence intensity $\left(I_{\mathrm{D}} / I_{\mathrm{M}}\right)$ in the fluorescence spectra of the copolymers is proportional to the product of $F_{\text {aa }}$ times $L_{\mathrm{a}}$ as expressed in eq $1,{ }^{23}$ where, in the present study, $F_{\text {aa }}$ and $L_{\text {a }}$ represent the diad fraction and mean sequence length of the 2-VN unit, respectively. Since $F_{\text {aa }}$ is unable to be calculated from the fluorescence spectral data, eq 1 is modified as follows. According to Harwood equation, ${ }^{24}$ the diad fraction $F_{\text {aa }}$ and mean sequence length $L_{\mathrm{a}}$ are given by eq 2 and eq 3 , respectively, where $f_{\mathrm{a}}$ is the molar fraction (in $\%$ ) of the $2-\mathrm{VN}$ unit in the copolymer and $\mathrm{R}$ is the run number in the copolymer chain. Introducing eq 2 and 3 into eq 1 gives eq 4 , which shows that $I_{\mathrm{D}} / I_{\mathrm{M}}$ is proportional to the product of $f_{\mathrm{a}}$ times $\left(L_{\mathrm{a}}-1\right)$. In a real $1: 1$ alternating copolymer, the mean sequence length is equal to 1 , and hence, $\left(L_{\mathrm{a}}-1\right)$ in eq 4 represents the extent of the deviation $\left(\Delta L_{\mathrm{a}}\right)$ from the $1: 1$ alternation in the mean sequence length. By introducing the experimental data of $I_{\mathrm{D}} / I_{\mathrm{M}}$ and $f_{\mathrm{a}}$, information on the mean sequence length of the $2-\mathrm{VN}$ unit can be obtained.

$$
I_{\mathrm{D}} / I_{\mathrm{M}}=k \cdot F_{\mathrm{aa}} \cdot L_{\mathrm{a}}
$$




$$
\begin{aligned}
& F_{\mathrm{aa}}=f_{\mathrm{a}}-R / 2 \\
& L_{\mathrm{a}}=2 f_{\mathrm{a}} / R \\
& I_{\mathrm{D}} / I_{\mathrm{M}}=k \cdot f_{\mathrm{a}} \cdot\left(L_{\mathrm{a}}-1\right)=k \cdot f_{\mathrm{a}} \cdot \Delta L_{\mathrm{a}}
\end{aligned}
$$

Table II lists the values of $k \Delta L_{\mathrm{a}}$ calculated from eq 4 for the poly(2-VN-co-MAn) obtained at various monomer feed compositions. The results show definitely that the mean sequence length of the 2-VN unit in the copolymer increases with the $2-\mathrm{VN}$ molar fraction in the monomer feed. The increase in the mean sequence length of the 2-VN unit in the copolymer indicates that the relative proportion of the 2-VN-2-VN diad fraction or the 2$\mathrm{VN}-2-\mathrm{VN}-2-\mathrm{VN}$ triad fraction is increased. That is, the copolymer produced at a low 2$\mathrm{VN}$ molar fraction in the monomer feed contains mostly the 2-VN unit as an isolated sequence; however, the copolymer tends to contain the 2-VN-2-VN diad sequence with increasing content of $2-\mathrm{VN}$ in the monomer feed. It is concluded that the microstructure of the poly(2-VN-co-MAn) varies significantly depending on the monomer feed composition: the 2-VN mean sequence length increases with the 2-VN molar fraction in the monomer feed. Although the copolymers produced at the $2-\mathrm{VN}$ feed molar ratio from 0.4 to 0.60

Table II. Fluorescence intensity ratios and relative extents of deviation from $1: 1$ alternation $\left(\Delta L_{\mathrm{a}}\right)$ for poly(2-VN-co-MAn) obtained at $60^{\circ} \mathrm{C}^{\mathrm{a}}$

\begin{tabular}{cccc}
\hline $\begin{array}{c}\text { 2-VN mole } \\
\text { fraction in } \\
\text { monomer feed }\end{array}$ & $\begin{array}{c}\text { 2-VN mole } \\
\text { fraction in } \\
\text { copolymer }\end{array}$ & $I_{400} / I_{338}{ }^{\mathrm{b}}$ & $k \cdot \Delta L_{\mathrm{a}}{ }^{\mathrm{c}}$ \\
\hline 0.30 & 0.46 & 0.19 & 0.41 \\
0.40 & 0.49 & 0.24 & 0.49 \\
0.50 & 0.50 & 0.31 & 0.62 \\
0.60 & 0.51 & 0.40 & 0.78 \\
0.70 & 0.53 & 0.58 & 1.1 \\
\hline
\end{tabular}

${ }^{\mathrm{a}}[2-\mathrm{VN}]+[\mathrm{MAn}]=1.0 \mathrm{~mol} \mathrm{dm}^{-3}$; solvent, benzene.

${ }^{b}$ Intensity ratio of the excimer fluorescence $(400 \mathrm{~nm})$ to monomer fluorescence $(338 \mathrm{~nm})$.

c Calculated from equation 4 using $f_{\mathrm{a}}$ in mole fraction instead of $\%: \Delta L=L_{\mathrm{a}}-1 ; L_{\mathrm{a}}, 2$-VN mean sequence length; $k$, constant. have nearly the equimolar composition, they are not real $1: 1$ alternating copolymers.

The copolymer composition is known to be affected by polymerization temperature. For example, copolymer compositions deviate from the equimolar one, becoming random at high temperatures, as reported for the styreneMAn and $\alpha$-methylstyrene-MAn 1:1 alternating copolymerization systems. ${ }^{25,26}$ It is of interest to examine how polymerization temperature affects the microstructures of copolymers resulting from the 2-VN-MAn system. In the present study, the copolymerization of 2-VN with MAn was carried out at several temperatures, and the fluorescence spectra of the resulting copolymers were measured.

Figure 3 shows the compositions of poly(2VN-co-MAn) obtained at several temperatures. In the temperature range from $0^{\circ} \mathrm{C}$ to $80^{\circ} \mathrm{C}$, copolymers with near equimolar compositions are obtained when the $2-\mathrm{VN}$ molar fraction is in the range from 0.4 to 0.6 . It seems

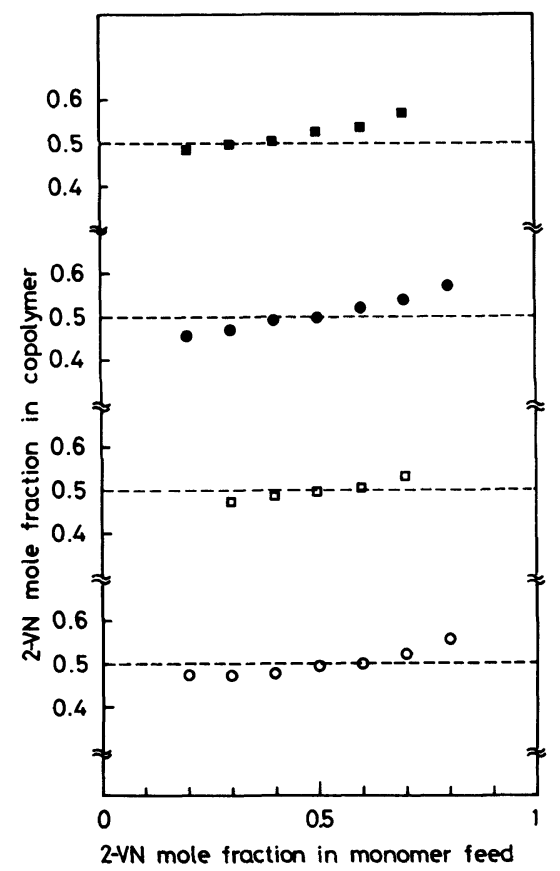

Figure 3. Compositions of poly(2-VN-co-MAn) obtained at several temperatures vs. monomer feed com-

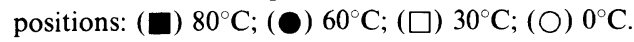




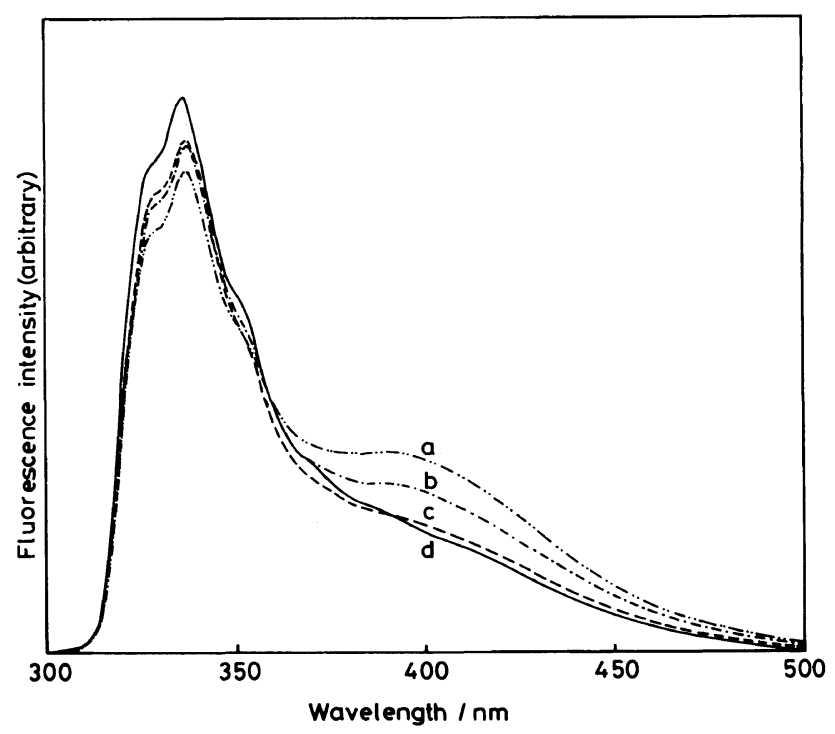

Figure 4. Fluorescence spectra of poly(2-VN-co-MAn) obtained for the equimolar monomer feed at several temperatures: a) $90^{\circ} \mathrm{C}$; b) $60^{\circ} \mathrm{C}$; c) $30^{\circ} \mathrm{C}$; d) $0^{\circ} \mathrm{C}$.

from the composition data that the polymerization temperature does not greatly affect the copolymer composition. Figure 4 shows the fluorescence spectra of poly(2-VN-co-MAn) obtained for the monomer feed molar ratio of $1: 1$ at different temperatures. The result shows that in spite of the fact that the copolymers have nearly $1: 1$ compositions, the fluorescence spectra of the copolymers depend significantly on the polymerization temperature: the relative intensity of the excimer fluorescence to the monomer fluorescence increases with polymerization temperature. Although polymerization temperature affects the molecular weight of the resulting copolymers, it is found that molecular weight does not greatly influence the relative fluorescence intensity ratio. For example, the copolymer prepared for the equimolar monomer feed at $60^{\circ} \mathrm{C}$ has a smaller molecular weight than the copolymer obtained at $30^{\circ} \mathrm{C}$; however, the relative fluorescence intensity ratio for the former copolymer is larger than that for the latter copolymer (Figure 4). The fact that the copolymer obtained at $0^{\circ} \mathrm{C}$ shows distinctly the excimer fluorescence indicates that a real $1: 1$ alternat-

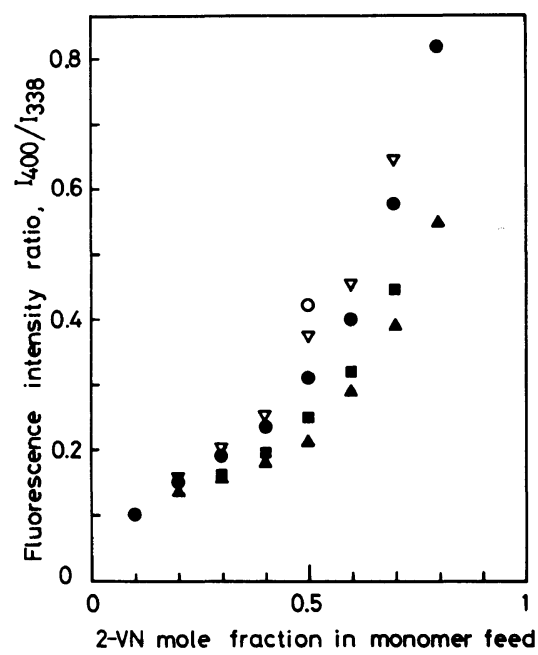

Figure 5. Fluorescence intensity ratios, $I_{400} / I_{338}$, of poly(2-VN-co-MAn) obtained at several temperatures vs. monomer feed compositions: $(\bigcirc) 90^{\circ} \mathrm{C}$; ( $\left.\nabla\right) 80^{\circ} \mathrm{C}$; (O) $60^{\circ} \mathrm{C} ;(\square) 30^{\circ} \mathrm{C} ;(\mathbf{\Delta}) 0^{\circ} \mathrm{C}$.

ing copolymer cannot be obtained even at a low polymerization temperature of $0^{\circ} \mathrm{C}$.

Figure 5 shows the relative intensity ratios of the excimer to the monomer fluorescence for poly(2-VN-co-MAn) obtained at different temperatures vs. monomer feed composition. 
Table III. Relative extent of deviation from $1: 1$ alternation $\left(\Delta L_{\mathrm{a}}\right)$ for $\operatorname{poly}(2-\mathrm{VN}-\mathrm{co}$-MAn) obtained at various temperatures ${ }^{\mathrm{a}}$

\begin{tabular}{cccc}
\hline $\begin{array}{c}\text { Polymerization } \\
\text { temperature }\end{array}$ & $\begin{array}{c}\text { 2-VN mole } \\
\text { fraction in } \\
\text { copolymer }\end{array}$ & $I_{400} / I_{338}{ }^{\mathrm{b}}$ & $k \cdot \Delta L_{\mathrm{a}}^{\mathrm{c}}$ \\
\hline${ }^{\circ} \mathrm{C}$ & & & \\
\hline 0 & 0.49 & 0.21 & 0.43 \\
30 & 0.50 & 0.25 & 0.50 \\
60 & 0.50 & 0.31 & 0.62 \\
80 & 0.52 & 0.37 & 0.71 \\
90 & 0.52 & 0.42 & 0.81 \\
\hline
\end{tabular}

a $[2-\mathrm{VN}]=0.5 \mathrm{~mol} \mathrm{dm}^{-3} ; \quad[\mathrm{MAn}]=0.5 \mathrm{~mol} \mathrm{dm}^{-3} ;$ solvent: toluene $\left(0^{\circ} \mathrm{C}\right)$; benzene $\left(30-90^{\circ} \mathrm{C}\right)$.

b Intensity ratio of the excimer fluorescence $(400 \mathrm{~nm})$ to the monomer fluorescence $(338 \mathrm{~nm})$.

c Calculated from equation 4 using $f_{\mathrm{a}}$ in mole fraction instead of $\%: \Delta L=L_{\mathrm{a}}-1 ; L_{\mathrm{a}}, 2-\mathrm{VN}$ mean sequence length; $k$, constant.

It is clearly shown that the relative fluorescence intensity ratios increase with the $2-\mathrm{VN}$ molar fraction in the monomer feed at the same temperature, and that the higher the polymerization temperature, the larger is the relative intensity of the excimer fluorescence over a wide range of monomer feed compositions.

Table III lists the values of $k \Delta L_{\mathrm{a}}$ calculated from eq 4 for poly(2-VN-co-MAn) obtained for the equimolar monomer feed composition at different temperatures. It is shown that the microstructure of poly(2-VN-co-MAn) is strongly influenced by polymerization temperature. When the polymerization temperature increases from $0^{\circ} \mathrm{C}$ to $90^{\circ} \mathrm{C}$, the mean sequence length of the 2-VN unit increases and the values of $k \Delta L_{\mathrm{a}}$ is almost doubled.

Although it is necessary to elucidate which model, terminal, penultimate, or chargetransfer model, explains most satisfactorily the propagation process of the present $2-\mathrm{VN}$ MAn system, reactions of the free monomers will surely be involved. Generally, the transition state of the cross-reaction will be more stabilized than the homoreaction in the electron-donor monomer-electron-acceptor monomer system. In the present system, the cross-propagation seems to be favored; however, the homo-reaction between the 2-VN free radical and $2-\mathrm{VN}$ monomer tends to occur with increasing concentration of the $2-\mathrm{VN}$ in the monomer feed. The cross-reaction will be more favored at a lower polymerization temperature; the selectivity in the reaction tends to decrease with increasing polymerization temperature.

The fluorescence spectroscopy characterization of the copolymer is a sensitive method for gaining information on the monomer sequence in the copolymer. Even when an increase in the proportion of the diad fraction does not greatly affect the copolymer composition, the increase in the $F_{\text {aa }}$ and hence $L_{\mathrm{a}}$ brings about more significant variation in $I_{\mathrm{D}} / I_{\mathrm{M}}$, which is proportional to the product of $F_{\text {aa }}$ times $L_{\mathrm{a}}$. In addition, the present method is simple and convenient because it requires only a few milligrams of samples for the measurement. The method can be applied to other copolymers with the aryl vinyl monomer as one component.

\section{CONCLUSION}

The fluorescence spectra of poly(2-VN-coMAn) obtained by the radical copolymerization of 2-VN with MAn were measured as a function of the monomer feed composition and polymerization temperature in order to gain information on the microstructure of the resulting copolymers. The copolymer exhibits both excimer and monomer fluorescence, and their intensity ratio depends significantly upon monomer composition and polymerization temperature. It is shown that the microstructure of the copolymer varies significantly depending on the monomer feed composition and on the polymerization temperature. The 2VN-2-VN diad fraction increases with the 2VN molar fraction in the monomer feed and with polymerization temperature. Although copolymers with an equimolar composition 
are obtained at the $2-\mathrm{VN}$ feed molar ratio from 0.4 to 0.6 , a real $1: 1$ alternating copolymer is not obtained even at $0^{\circ} \mathrm{C}$ in the $2-\mathrm{VN}-\mathrm{MAn}$ system.

The fluorescence spectroscopy characterization of the copolymer provides useful information on the microstructure of copolymers with aryl vinyl monomers as one component.

\section{REFERENCES}

1. J. M. G. Cowie, Ed., "Alternating Copolymers," Plenum Press, New York, N.Y., 1985.

2. Y. Shirota, "Encyclopedia of Polymer Science and Engineering," Vol. 3, John Wiley \& Sons, Inc., New York, N.Y., 1985, p 327.

3. D. J. T. Hill, J. H. O'Donnell, and P. W. O'Sullivan, Prog. Polym. Sci., 8, 215 (1982).

4. H. Hirai, J. Polym. Sci., Macromol. Rev., 11, 47 (1976).

5. D. J. T. Hill, J. H. O'Donnell, and P. W. O'Sullivan, Macromolecules, 18, 9 (1985), and references cited therein.

6. P. F. Barron, D. J. T. Hill, J. H. O’Donnell, and P. W. O’Sullivan, Macromolecules, 17, 1967 (1984), and references cited therein.

7. R. B. Fox, T. R. Price, R. F. Cozzens, and W. H. Echols, Macromolecules, 7, 937 (1974).

8. T. Hirabayashi, Y. Nishikawa, and K. Yokota, J. Polym. Sci., 17, 3823 (1979).

9. F. Bai, C. H. Chang, and S. E. Webber, Macromolecules, 19, 588 (1986).

10. Y. Morishima, T. Kobayashi, S. Nozakura, and S. E.
Webber, Macromolecules, 20, 807 (1987).

11. Y. Shirota, A. Matsumoto, and H. Mikawa, Polym. J., 3, 643 (1972).

12. M. Yoshimura, Y. Shirota, and H. Mikawa, $J$. Polym. Sci., B, 11, 457 (1973).

13. Y. Shirota, M. Yoshimura, A. Matsumoto, and H. Mikawa, Macromolecules, 7, 4 (1974).

14. M. Yoshimura, H. Mikawa, and Y. Shirota, Macromolecules, 8, 723 (1975).

15. M. Yoshimura, T. Nogami, M. Yokoyama, $\mathrm{H}$. Mikawa, and Y. Shirota, Macromolecules, 9, 211 (1976).

16. M. Yoshimura, H. Mikawa, and Y. Shirota, Macromolecules, 11, 1085 (1978).

17. Y. Shirota, K. Takemura, H. Mikawa, T. Kawamura, and K. Matsuzaki, Makromol. Chem., Rapid Commun., 3, 913 (1982).

18. G.-J. Jiang, Y. Shirota, and H. Mikawa, Polym. Bull., 14, 447 (1985).

19. M. Yokoyama, T. Tamamura, M. Atsumi, M. Yoshimura, Y. Shirota, and H. Mikawa, Macromolecules, 8, 102 (1975).

20. W. Zeng and Y. Shirota, Polym. Prepr. Jpn., 35, 1552 (1986); Chem. Express, 3, 719 (1988).

21. R. B. Fox, T. R. Price, R. F. Cozzens, and J. R. McDonald, J. Chem. Phys., 57, 534 (1972).

22. C. David, M. Piens, and G. Gueskens, Eur. Polym. J., 8, 1019 (1972).

23. R. F. Reid and I. J. Soutar, J. Polym. Sci., Polym. Lett. Ed., 15, 153 (1977).

24. H. J. Harwood and W. M. Ritchey, J. Polym. Sci., Polym. Lett. Ed., 2, 601 (1964).

25. R. B. Seymour and D. P. Garner, J. Coatings Technol., 41, 612 (1976).

26. R. B. Seymour and D. P. Garner, Polymer, 17, 21 (1976). 